\title{
The influence of hierarchical zeolite composition and pore structure on behavior of cobalt-based Fischer-Tropsch synthesis catalysts
}

\author{
Weiming Zhao ${ }^{1}$ Yuelun Wang ${ }^{1} \cdot{\mathrm{Zhuo} \mathrm{Li}^{2} \cdot \text { Hui Wang }}^{2} \cdot$ Jinhu $\mathrm{Wu}^{2} \cdot$ \\ Jun Huang ${ }^{1}$ Y Yunpeng Zhao ${ }^{1}$
}

(C) Springer Science+Business Media New York 2015

\begin{abstract}
Cobalt catalyst supported on hierarchical zeolite possessing a three different $\mathrm{Si} / \mathrm{Al}$ ratio was studied in Fischer-Tropsch synthesis. The catalyst with $\mathrm{Si} / \mathrm{Al}$ ratio of 60 was found to be superior to other catalysts in terms of better $\mathrm{C}_{5-18}$ selectivity and higher olefin/paraffin ratio due to smaller cobalt particles and larger number of acidic sites. While Co/Meso-ZSM120 catalyst with perfect crystal structure favored products to accessibility and prevented cobalt particles from being oxidized compared to that of amorphous support, resulting in the lowest deactivation rate and the lowest carbon content on the surface.
\end{abstract}

Keywords Hierarchical zeolites $\cdot \mathrm{Si} / \mathrm{Al}$ ratio $\cdot$ Cobalt catalyst $\cdot$ Deactivation $\cdot$ Fischer-Tropsch synthesis

\section{Introduction}

As one of the most promising routes to solve the energy crisis, converting syngas $\left(\mathrm{CO}+\mathrm{H}_{2}\right)$ to liquid oil by Fischer-Tropsch synthesis (FT synthesis) has attracted more and more attention [1-3]. Co-based catalysts are often the choice for low temperature FT synthesis due to the high stability, high conversion, and high selectivity to linear paraffins, low water-gas shift (WGS) activity, and

Yuelun Wang

wangyuelun@126.com

1 Key Laboratory of Coal Processing and Efficient Utilization, Ministry of Education, School of Chemical Engineering, China University of Mining and Technology, Xuzhou 221116, Jiangsu, China

2 Key Laboratory of Biofuel, Chinese Academy of Sciences, Qingdao Institute of Bioenergy and Bioprocess Technology, Qingdao 266101, China relatively low price $[4,5]$. However, linear paraffins are predominate in FT synthesis, and their distribution follows the Anderson-Schultz-Flory (ASF) law. It is not easy to directly synthesize hydrocarbons with narrow, specified carbon number distribution from FT reaction alone. Furthermore, hydrocracking and isomerization by acidic zeolite are often utilized to convert the heavy FT linear hydrocarbons into liquid fuels.

To directly obtain branched hydrocarbons through FT synthesis without further upgrading of FT products, intensive efforts have been dedicated to modifying cobaltbased catalysts. The catalysts combing with zeolites which were used in isoparaffins synthesis have become a focus of attention over years [6-12]. But in these catalytic systems, the primary hydrocarbon products migrated into micropores of zeolites where the hydrocracking occurs, then the products must diffuse out of the micropores. Such slow transportation of products usually causes over-cracking, resulting in high selectivity of $\mathrm{CH}_{4}$. The strong acidity of zeolites may also cause the over-cracking of hydrocarbon products. Moreover, these catalysts often suffered very low $\mathrm{CO}$ conversion. Their extremely low reduction degree originated from strong interactions of cobalt with zeolites.

Recently, zeolites with hierarchically porous structures have garnered much attention due to their highly attractive properties. Because they combine the catalytic features of micropores and the increased molecular transport within a single body [13-15]. The use of mesoporous zeolites as supports gave promising perspective for FTS [16-18]. Mesoporous H-ZSM-5 zeolites with FTS active phases have demonstrated that the intimate contact between the FTS metal and the acid sites of mesoporous zeolites turned out to be the key parameter, determining the performance of such catalysts in tuning the product selectivity. When acid site domains are in a close vicinity to FTS sites, the 
produced olefinic FTS hydrocarbons may crack or isomerize before they are hydrogenated. Besides, the improved transport properties of hierarchically structured zeolites increase the selectivity toward liquid hydrocarbons. Their high mesopore surface area improves cobalt dispersion at elevated metal loadings. However, limited knowledge is available on the actual role of zeolite acidity and on the influence of the zeolite support on the Co active phase. In this work, a detailed of evaluation of catalyst performance combined with a characterization to understand the bifunctional FTS catalysts with three different $\mathrm{Si} /$ $\mathrm{Al}$ ratios of 60,80 and 120 was carried out.

\section{Experimental}

\subsection{Samples preparation}

Mesoporous ZSM-5 was prepared as follows: first, $2.409 \mathrm{~g}$ of sodium aluminate were dissolved in $30 \mathrm{~mL}$ of tetrapropylammonium hydroxide $(25 \%)$, together with $65.5 \mathrm{ml}$ of water and $0.191 \mathrm{~g}$ of sodium hydroxide, a certain amount of TEOS, prepared with $\mathrm{Si} / \mathrm{Al}$ molar ratio of $60,80,120$, respectively, were added to this solution. After homogenization, cetyltrimethylammonium bromide solution (CTAB) was added. The suspension obtained was maintained under mechanical agitation for $2 \mathrm{~h}$. The mixture was heated at $413 \mathrm{~K}$ and kept at this temperature for $72 \mathrm{~h}$ in hydrothermal vessel. The obtained solid by centrifugation was washed with deionized water and then dried at $333 \mathrm{~K}$ for $12 \mathrm{~h}$. The sample was then calcined at $823 \mathrm{~K}$ for $5 \mathrm{~h}$. Ion exchange was performed using $1 \mathrm{M}$ solution of $\mathrm{NH}_{4} \mathrm{NO}_{3}$ at $353 \mathrm{~K}$ for $4 \mathrm{~h}$ by two consecutive similar processes. After the ion exchange, the zeolite was filtered and washed with enough de-ionized water and after that dried in oven at $363 \mathrm{~K}$ overnight, the $\mathrm{NH}_{4}$-zeolite was calcined in the static air at $773 \mathrm{~K}$ for $3 \mathrm{~h}$ to obtain meso-Hzeolite. The synthesized materials were named as MesoZSM60, Meso-ZSM80 and Meso-ZSM120 corresponding to $\mathrm{Si} / \mathrm{Al}$ molar ratio of $60,80,120$, respectively.

The supported cobalt catalysts were prepared by incipient wetness impregnation method. $3 \mathrm{~g}$ of different supports were completely wetted with deionized water to evaluate the corresponding volume. Then, cobalt nitrate was dissolved into the required deionized water to impregnate the supports with the loading of $15 \%$. The catalysts were then dried under temperature of $333 \mathrm{~K}$ and calcined at $673 \mathrm{~K}$ for $4 \mathrm{~h}$. The obtained catalysts were named Co/Meso-ZSM60 catalyst, Co/Meso-ZSM80 catalyst, Co/Meso-ZSM120 catalyst, respectively. The real cobalt mass content was analyzed by inductively coupled plasma (ICP) technique. A slight change between the design value and the actual value was obtained.

\subsection{Characterization}

The textural properties of supports and catalysts were determined by nitrogen adsorption and Ar adsorption, in a Micromeritics equipment. The surface area was calculated using the Brunauer-Emmett-Teller (BET) method. The pore size distribution was determined by NLDFT method.

$\mathrm{X}$-ray diffraction (XRD) patterns of the samples were recorded on a Bruker B5005 diffractometer using $\mathrm{Cu} \mathrm{Ka}$ radiation. The mean $\mathrm{Co}_{3} \mathrm{O}_{4}$ crystallite sizes were deduced from the XRD data using the Scherrer equation.

TPR was carried out in a U-tube quartz reactor at the ramp rate of $10 \mathrm{~K} / \mathrm{min}$ in the $5 \% \mathrm{H}_{2} / \mathrm{Ar}$ (vol.) flow of $30 \mathrm{ml} / \mathrm{min}$. The $\mathrm{H}_{2}$ consumption was monitored with TCD using the reduction of $\mathrm{CuO}$ as the standard. The reduction percentage of the cobalt oxides was calculated from the TPR profiles.

Temperature-programmed desorption of ammonia was performed with a Chem TPR/TPD instrument (Quantachrome). Approximately $80 \mathrm{mg}$ catalyst was activated for $1 \mathrm{~h}$ at $773 \mathrm{~K}$ heating with a ramp of $10 \mathrm{~K} / \mathrm{min}$. After cooling to $473 \mathrm{~K}$, pure ammonia was passed through the sample. The desorption of the ammonia was accomplished by purging helium with a flow of $20 \mathrm{ml} / \mathrm{min}$ and raising the temperature to $1073 \mathrm{~K}$. The effluent gas was analyzed by an on-line gas chromatograph with a TCD detector.

TEM was performed with an FEI Tecnai TF20 microscope using a carbon-coated $\mathrm{Cu}$ grid.

\subsection{Catalytic experiments}

$1 \mathrm{~g}$ of catalysts were evaluated in a pressured fixed-bed reactor at $2 \mathrm{MPa}, 1000 \mathrm{~h}^{-1}$ with $\mathrm{H}_{2} / \mathrm{CO}$ ratio of 2 after reduction at $673 \mathrm{~K}$ for $10 \mathrm{~h}$. Wax was collected with a hot trap and the liquid products were collected in a cold trap. The gas effluents were analyzed on-line by using carbon molecular sieve column with TCD. The gas hydrocarbons were analyzed on-line using Porapack-Q column with FID. Oil and wax were analyzed offline in OV-101 capillary columns. $5 \% \mathrm{~N}_{2}$ was added to syngas as an internal standard. The carbon balance and mass balance were $100 \pm 5 \%$.

\section{Results and discussion}

The $\mathrm{N}_{2}$ physisorption isotherms of cobalt supported hierarchical zeolites were presented in Fig. 1. The isotherm of catalysts exhibited the composite isotherms consisted of types II and IV, indicating the existence of micropore and mesopore structures, respectively. Moreover, the shape of the hysteresis loops of supports fell within the $\mathrm{H}_{3}$ category [19], which was attributed to slit-type pores associated with 


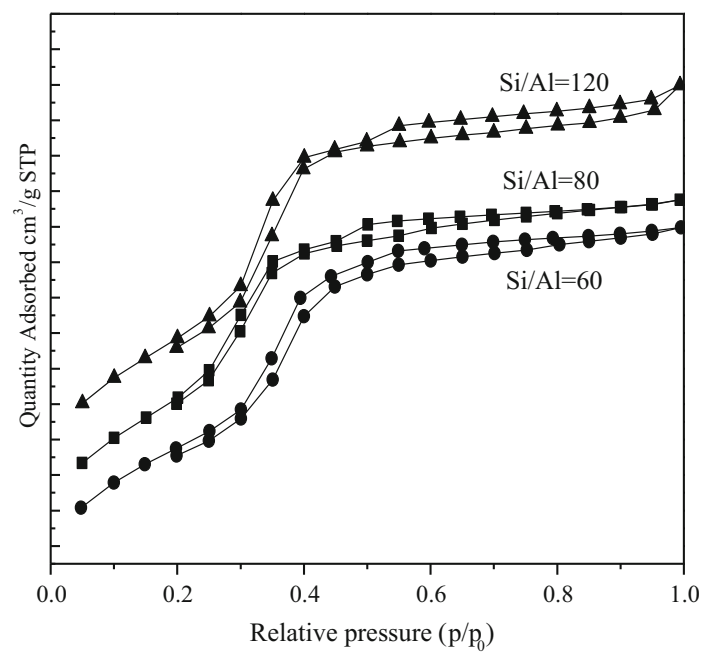

Fig. $1 \mathrm{~N}_{2}$ adsorption/desorption isotherm of catalysts at $70 \mathrm{~K}$

the interparticle porosity generated in solids. The abrupt increase observed in the region of $0.2<\mathrm{P} / \mathrm{P}_{0}<0.4$ was a result of micropore filling. The second mild increase within the $0.5<\mathrm{P} / \mathrm{P}_{0}<0.9$ region indicated capillary condensation of $\mathrm{N}_{2}$ in mesopores. Figure 2 displayed the pore size distribution of samples. We can note that hierarchical zeolites showed a bimodal distribution with the narrow porosity around $0-2$ and 3-5 nm, respectively. The specific surface areas for unloaded supports and loaded supports were reconfirmed by Ar adsorption-desorption analysis. The results of textural properties of supports and catalysts with argon gas are shown in Table 1. It was observed that the change trend of loaded supports was consistent with that of unloaded supports with different Si/Al ratios. An increase on the area of the samples was observed with the increase of $\mathrm{Si} / \mathrm{Al}$ molar ratio. As a consequence, $\mathrm{Co} / \mathrm{Meso}-$ ZSM60 catalyst showed the lowest specific surface area and the lowest mesopore volume, while the highest surface

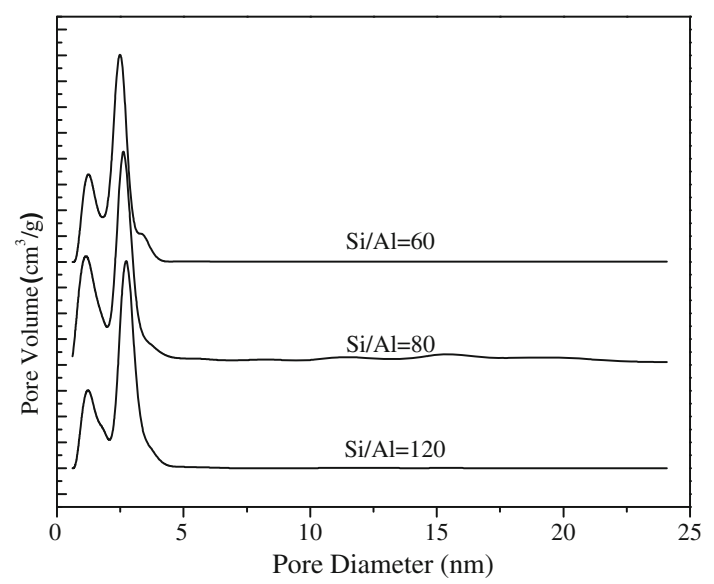

Fig. 2 Pore size distribution of catalysts area and the largest mesopore volume were found over $\mathrm{Co} /$ Meso-ZSM120 catalyst. And its total pore volume increased from 0.91 to $1.01 \mathrm{~cm}^{3} / \mathrm{g}$, which was due to the creation of more mesopores at the cost of a slight decrease in the micropore volume.

The XRD patterns of Co supported catalysts are presented in Fig. 3. All catalysts showed the characteristic reflection peak at $2 \theta=36.8^{\circ}, 44.8^{\circ}, 59.3^{\circ}$, and $65.2^{\circ}$ due to the presence of $\mathrm{Co}_{3} \mathrm{O}_{4}$ phase $[20,21]$. The particle size of $\mathrm{Co}_{3} \mathrm{O}_{4}$ is calculated by using Scherrer's equation. The crystallite size of $\mathrm{Co}_{3} \mathrm{O}_{4}$ was found to increase slightly with the increase of $\mathrm{Si} / \mathrm{Al}$ ratio of hierarchical zeolites, i.e., cobalt particle size of $12.4,14.2$ and $15.8 \mathrm{~nm}$ on cobalt catalyst having $\mathrm{Si} / \mathrm{Al}$ ratios of 60,80 and 120 as summarized in Table 1. Additionally, the characteristic peaks of MFI structure were observed on Co/Meso-ZSM120 catalyst. There was a diminution of XRD peaks intensities with decreasing Si/Al molar ratio, i.e., Co/Meso-ZSM60 catalyst, presented a strong diminution of the zeolite XRD peaks intensity, suggesting the amorphism structures were present.

Figure 4 displays the TPR profiles of catalysts, where one observed three peaks corresponding to the transitions of $\mathrm{Co}_{3} \mathrm{O}_{4}$. The first peak was assigned to the reduction of the $\mathrm{Co}^{3+}$ phase to $\mathrm{Co}^{2+}$ at about $598 \mathrm{~K}$ for the catalysts with $\mathrm{Si} / \mathrm{Al}$ ratio of 80 and 120 , while Co/Meso-ZSM60 catalyst showed this reduction peak at about $623 \mathrm{~K}$ due to smaller particles of cobalt oxide. The second peak occurred at a higher temperature corresponding to the transition $\mathrm{Co}^{2+} \rightarrow \mathrm{Co}^{0}$. With the increase of $\mathrm{Co}_{3} \mathrm{O}_{4}$ particle sizes, the positions of the peaks shifted to lower temperatures, which suggested that larger particles were more facilitated the rate of Co reduction. However, the third peak overlapped and extended over a wide temperature range, indicating several interactions occurring between the cobalt species and the surface of supports, which led to the formation of unreductive cobalt aluminates or cobalt silicates. With the decrease of $\mathrm{Si} / \mathrm{Al}$ ratios, the areas of reduction peak were increased indicated that the cobalt-support interaction became more complicated and stronger [22, 23]. The reduction degree was relatively expressed as the ratio of the amount of $\mathrm{H}_{2}$ consumption below $673 \mathrm{~K}$ to that of total $\mathrm{H}_{2}$ consumption. The values were $69.3,73.2,78.4 \%$ for the catalysts with $\mathrm{Si} / \mathrm{Al}$ ratio of $60,80,120$, respectively, as shown in Table 1.

The morphology of coalt supported mesoporous ZSM-5 was verified using TEM. For Co/Meso-ZSM120 catalyst, the small zeolitic MFI particles (Fig. 5a) lied at the edges of the mesoporous phase which was partly worm-like (Fig. 5b). For Co/Meso-ZSM60 catalyst, amorphous structure was observed. These demonstrated that the material with zeolitic features with retaining a narrow mesoporous distribution was a composite and not a true 
Table 1 Texture and phase structure properties of supports and cobalt catalysts

\begin{tabular}{|c|c|c|c|c|c|c|c|c|}
\hline Samples & $\begin{array}{l}\text { Specific surface } \\
\text { area }\left(\mathrm{m}^{2} / \mathrm{g}\right)\end{array}$ & $\begin{array}{l}\text { Micropore } \\
\text { size }(\mathrm{nm})\end{array}$ & $\begin{array}{l}\text { Mesopore } \\
\text { size }(\mathrm{nm})\end{array}$ & $\begin{array}{l}V_{\text {micro }} \\
\left(\mathrm{cm}^{3} / \mathrm{g}\right)\end{array}$ & $\begin{array}{l}V_{\text {meso }} \\
\left(\mathrm{cm}^{3} / \mathrm{g}\right)\end{array}$ & $\begin{array}{l}\text { Average } \mathrm{Co}_{3} \mathrm{O}_{4} \\
\text { particlesize }(\mathrm{nm})\end{array}$ & $\begin{array}{l}\text { Reducibility } \\
(100 \%)\end{array}$ & $\begin{array}{l}\text { Total acid sites } \\
\left(\text { mmoles } \mathrm{NH}_{3} / \mathrm{g}\right)\end{array}$ \\
\hline MZ60 & 976 & 1.8 & 4.5 & 0.67 & 0.32 & & & \\
\hline MZ80 & 1098 & 1.3 & 4.3 & 0.62 & 0.38 & & & \\
\hline MZ120 & 1198 & 1.6 & 4.7 & 0.60 & 0.53 & & & \\
\hline $\mathrm{Co} / \mathrm{MZ60}$ & 792 & 1.8 & 4.0 & 0.63 & 0.28 & 12.4 & 69.3 & 0.67 \\
\hline $\mathrm{Co} / \mathrm{MZ80}$ & 912 & 1.2 & 4.2 & 0.58 & 0.35 & 14.2 & 73.2 & 0.56 \\
\hline $\mathrm{Co} / \mathrm{MZ120}$ & 1014 & 1.5 & 4.5 & 0.56 & 0.45 & 15.8 & 78.4 & 0.37 \\
\hline
\end{tabular}

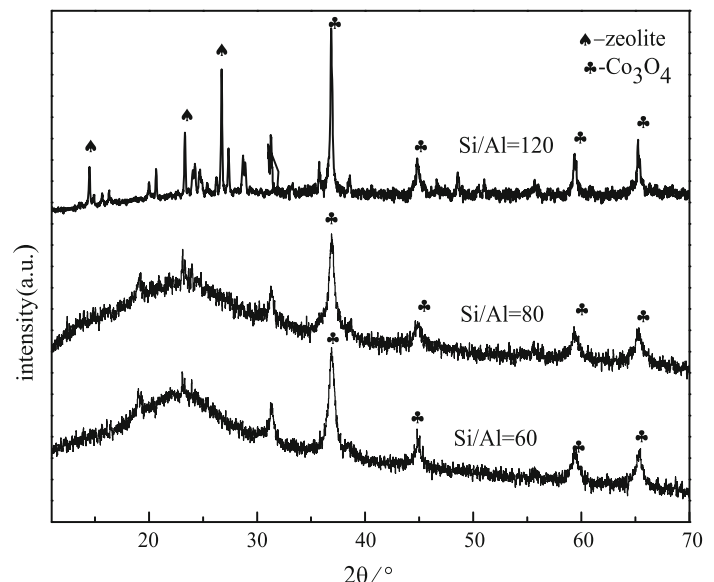

Fig. 3 XRD profiles of the prepared catalysts

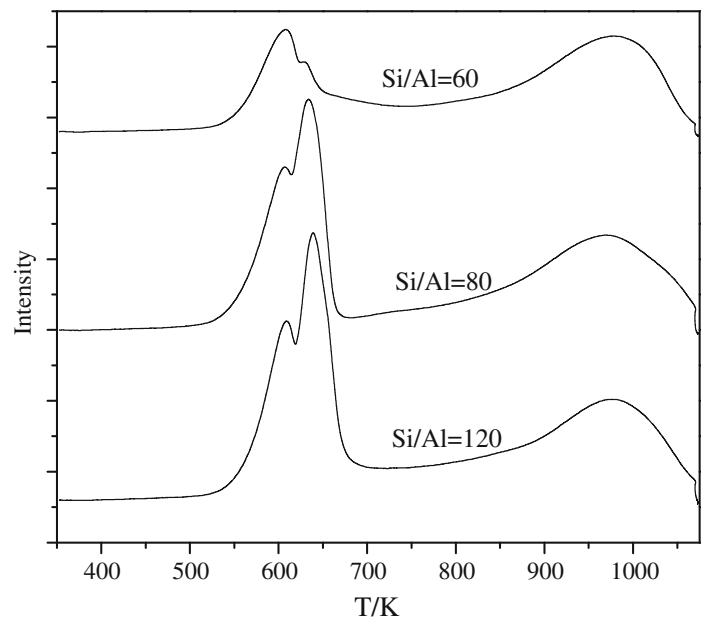

Fig. 4 TPR profiles of the prepared catalysts

interconnected hierarchical mesoporous zeolite. The presence of separate mesoporous and zeolitic phases was due to the underlying competition in interaction between zeolite and mesopore formation [24]. TEM images also showed that Co oxide crystallites of about $10-50 \mathrm{~nm}$ were located in the interconnected pores of meso-ZSM-5 particles.
Further, some Co crystallites were visibly tended to cluster on the support.

The $\mathrm{NH}_{3}$-TPD patterns of the FT catalysts are shown in Fig. 6 and two $\mathrm{NH}_{3}$ desorption peaks were observed. The lower-temperature peak centered at $453-523 \mathrm{~K}$ could be assigned to ammonia desorption over the weak acid sites [18]. It was observed that the intensity of weak acid sites was higher on Co/Meso-ZSM60 catalyst, in the first desorption temperature region, which was ascribed to be the presence of a higher amount of $\mathrm{Al}$ species in Co/MesoZSM60 catalyst [25]. A broad peak at 573-993 K, which could be attributed to the adsorption of acid sites, was observed. The peak at approximately $723 \mathrm{~K}$ was ascribed to the strong acid sites. Table 1 gives the number of acid sites expressed as $\mathrm{mmol} \mathrm{NH}_{3} / \mathrm{g}$ of catalyst with respect to only weak and strong acidic sites. By considering first peak only (weak acid sites), the total number of acid sites varied in the order of $\mathrm{Si} / \mathrm{Al}=60,80,120$. As a coincidence, the acidity decreased proportionately with the increase in $\mathrm{Si} / \mathrm{Al}$ ratio of the support. Besides, the intensity of desorption peak at $723 \mathrm{~K}$ decreased remarkably when $\mathrm{Si} / \mathrm{Al}$ ratio increased, which was easy to understand that there was less acidity of strong acid sites at lower aluminum concentration. The cobalt particle size may have an influence on the surface acidity. A weaker interaction was present between larger cobalt particles and the support with lower surface acid sites.

The catalytic performance on cobalt catalysts was measured at $503 \mathrm{~K}$. The activity of Co/Meso-ZSM120 catalyst was the highest among the catalysts. That is, $\mathrm{CO}$ conversion proportionately increased with the increase of $\mathrm{Si} / \mathrm{Al}$ ratio and this trend also correlated with cobalt particle sizes in larger mesopores as shown in Table 1. These larger particle sizes were responsible for higher reducibility of catalysts, which was found to be preferable for better $\mathrm{CO}$ conversion. Co/Meso-ZSM60 catalyst showed the lowest activity due to strong acidity of the support and the high dispersion of cobalt particles which resulted in less active sites for the chemisorption of $\mathrm{CO}$, and thus in a decrease of activity. 

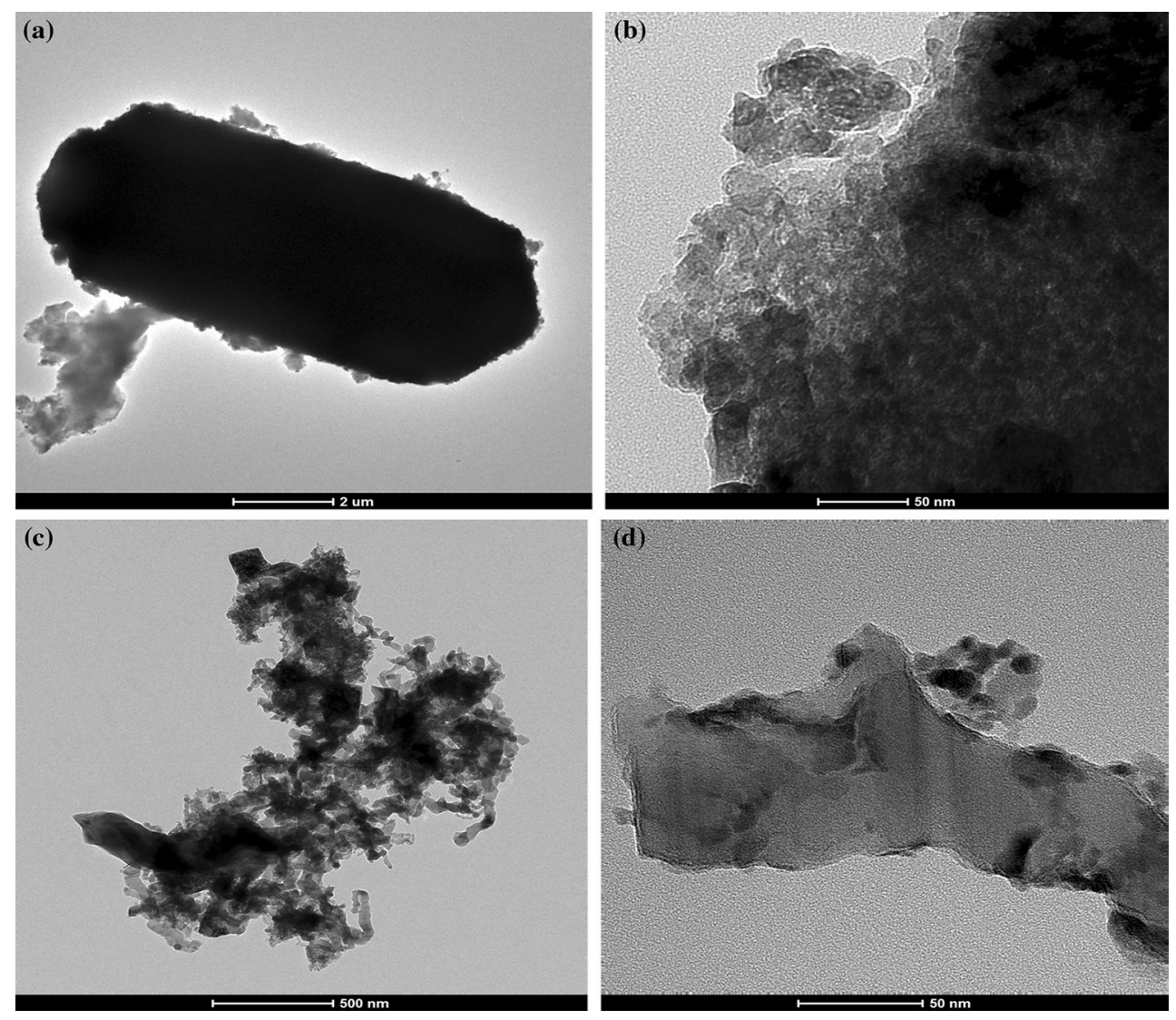

Fig. 5 TEM of Co/Meso-ZSM120 (a), Co/Meso-ZSM120 (b), Co/Meso-ZSM60 (c) Co/Meso-ZSM60 (d)

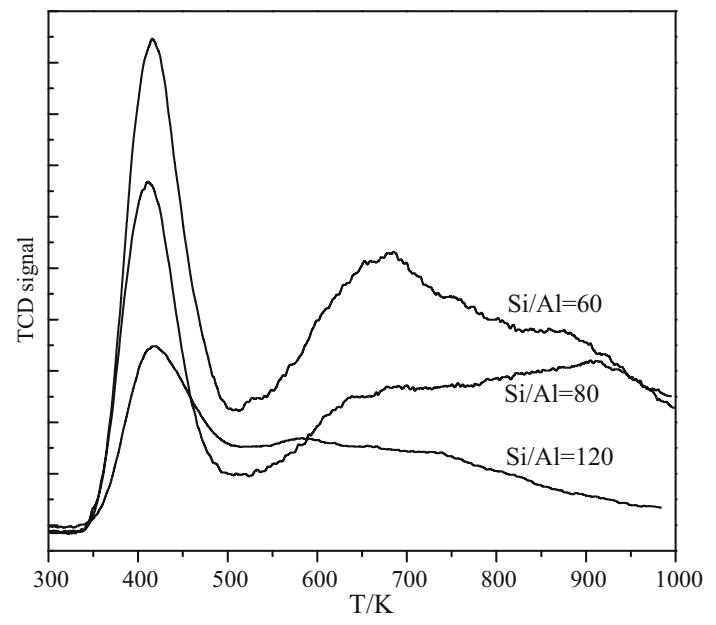

Fig. $6 \mathrm{NH}_{3}$-TPD profiles of catalysts

The selectivities of the FTS catalysts were significantly depending on their pore structure as showed in Table 2. The catalyst having smaller pore sizes tended to produce lighter hydrocarbons. As the pore size was larger, primary products transported more effectively and relevantly methane formation rate from secondary hydrocracking of olefins was lower. Accordingly the proportion of the heavy hydrocarbon was higher. In this study, zeolites with hierarchically porous structures combined the catalytic features of micropores and the increased molecular transport within a single body. The formation of the hierarchical composite catalysts with both zeolite and mesoporous materials gave rise to the increase of middle distillates because large space of the mesoporous material in zeolite promoted the generation of the more bulky branched hydrocarbons and decreased the selectivity of methane in FT synthesis. Co/ Meso-ZSM120 catalyst showed the highest selectivity towards $\mathrm{C}_{18+}$ hydrocarbon products due to the presence of larger mesopores with the increased transport properties of FT products and larger cobalt particles resulting in higher reducibility.

A lower olefin/paraffin (O/P) was also observed due to higher activity of hydrogenation and the suppressed olefin cracking properties of heavy olefinic products over lower acid sites [26]. Since the presence of strong acid sites on zeolite was responsible for the formation of isomers and aromatics [27], the ratio of isoparaffins to n-paraffins in the range of $\mathrm{C}_{5-18}$ (denoted as $\mathrm{C}_{\mathrm{iso}} / \mathrm{C}_{\mathrm{n}}$ ), an indicator of the quality of middle distillates, also increased with the increase of acid sites due to the secondary reactions, 
Table 2 Catalytic performance of cobalt catalysts in FT synthesis

\begin{tabular}{lllllllll}
\hline Catalyst & CO conversion $(\%)$ & $\mathrm{C}_{1}(\%)$ & $\mathrm{C}_{2-4}(\%)$ & $\mathrm{C}_{5-18}(\%)$ & $\mathrm{C}_{18+}(\%)$ & $\mathrm{O} / \mathrm{P}^{\mathrm{a}}$ & $\mathrm{C}_{\mathrm{iso}} / \mathrm{C}_{\mathrm{n}}{ }^{\mathrm{b}}$ & Deactivation rate $^{\mathrm{c}}$ \\
\hline Co/Meso-ZSM60 & 42.3 & 20.5 & 9.6 & 61.7 & 8.2 & 0.68 & 0.81 & 0.78 \\
Co/Meso-ZSM80 & 56.2 & 19.4 & 9.4 & 60.7 & 10.5 & 0.57 & 0.70 & 0.64 \\
Co/Meso-ZSM120 & 67.5 & 19.2 & 8.6 & 59.6 & 12.6 & 0.48 & 0.52 & 0.19 \\
\hline
\end{tabular}

Reaction conditions: $\mathrm{H}_{2} / \mathrm{CO}=2, \mathrm{GHSV}=1000 \mathrm{~h}^{-1}, \mathrm{P}=2 \mathrm{MPa}, \mathrm{T}=503 \mathrm{~K}$, TOS $=24 \mathrm{~h}$

${ }^{\text {a }} \mathrm{O} / \mathrm{P}$ stands for the olefin-to-paraffin ratio in the range of $\mathrm{C}_{1}-\mathrm{C}_{30}$ hydrocarbons

${ }^{b} \mathrm{C}_{\mathrm{iso}} / \mathrm{C}_{\mathrm{n}}$ stands forisoparaffin to n-paraffin in the range $\mathrm{C}_{5}-\mathrm{C}_{18}$

c deactivation rate: (CO conv. at $24 \mathrm{~h}-\mathrm{CO}$ conv. at $312 \mathrm{~h}) /(\mathrm{CO}$ conv. at $24 \mathrm{~h}) \times 100$

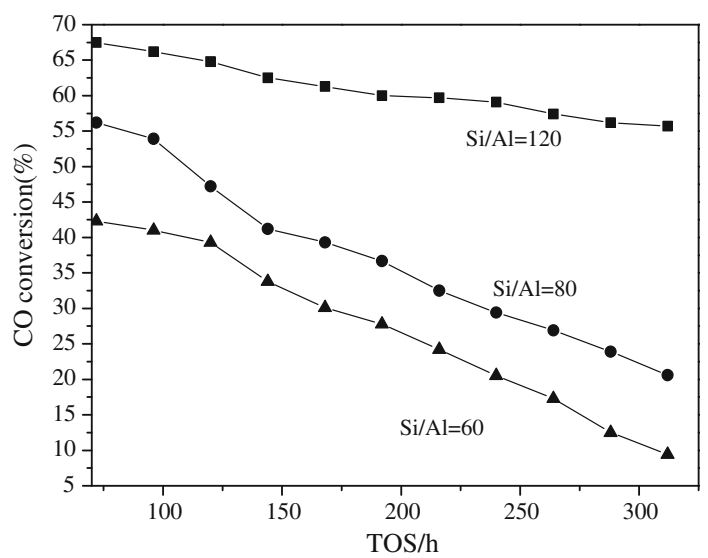

Fig. 7 TOS evolution of CO conversion during FTS at $503 \mathrm{~K}$

including hydrocracking and isomerization of the primary hydrocarbons over the acid sites. The high amounts of acidic sites on the catalyst having a low $\mathrm{Si} / \mathrm{Al}$ ratio were responsible for obtaining a high selectivity to olefins and $\mathrm{C}_{5-18}$ hydrocarbons. Meanwhile, a higher methane selectivity was observed over Co/Meso-ZSM60 catalyst, which was ascribed that lower reducibility of the catalyst led to lower probability of carbon-chain propagation and higher acid sites facilitated hydrocracking reactions.

A gradual deactivation of the catalysts with time-onstream was observed in Fig. 7. The deactivation rate was calculated and compared to the stability of catalysts in Table 2. It was observed that Co/Meso-ZSM60 catalyst and Co/Meso-ZSM80 showed similar deactivation rate. The fastest rate of deactivation was observed over $\mathrm{Co} /$ Meso-ZSM80 catalyst, even though it possessed more acid sites than that of Co/Meso-ZSM120 catalyst. The reason might be related to the different structure of the supports. XRD results showed that Co/Meso-ZSM120 catalyst had perfect crystal structure of ZSM-5, which could prevent particles from being oxidized by water and stabilize cobalt active sites compared to that of amorphous support. It was suggested that water produced increased the oxidation- reduction cycles on the catalyst surfaces, therefore leading to the growth and sintering of active metallic sites [25]. Moreover, the largest pore volume was found over $\mathrm{Co} /$ Meso-ZSM120 catalyst, the products including water removed easier, preventing from the rapid buildup of inactivating species. Thus, the catalyst showed the highest stability among the catalysts.

The crystallinity of mesoporous ZSM5 to the possible cobalt reoxidation was verified by measuring the oxidation states of cobalt particles on the used catalysts through XPS analysis (Fig. 8). The binding energies, as well as the percentage of each species, are summarized in Table 3, the three phases $\mathrm{Co}_{3} \mathrm{O}_{4}, \mathrm{CoO}$ and metallic cobalt are represented. For all samples the doublet separation of the binding energy $(\Delta \mathrm{E})$ between the Co $2 \mathrm{p}^{1 / 2}$ and Co $2 \mathrm{p}^{3 / 2}$ peaks was $14.8-15.4 \mathrm{eV}$, which was close to that of the mixed-valence $\mathrm{Co}_{3} \mathrm{O}_{4}(15.2 \mathrm{eV})$ [28]. Therefore, $\mathrm{Co}_{3} \mathrm{O}_{4}$ was considered the predominant cobalt phase in used catalysts. The reason might be that metal cobalt was oxidized during the FT reaction then exposed atmosphere after being taken out of reactors. It was noted that the catalysts exhibited a remarkably higher ratio of oxidic $\mathrm{Co}^{2+}$ to oxidic $\mathrm{Co}^{3+}$ than $\mathrm{Co}_{3} \mathrm{O}_{4}$. This indicated that some cobalt species existed in the state of $\mathrm{CoO}$ or a possibility that cobalt interacted either with $\mathrm{Al}$ or $\mathrm{Si}$ oxides. The peak intensity of $\mathrm{Co} 2 \mathrm{p}^{3 / 2}$ became enhanced with decreasing $\mathrm{Si} / \mathrm{Al}$ ratios, indicating the increased content of $\mathrm{Co}_{3} \mathrm{O}_{4}$ on the catalyst surfaces. The surface atomic ratio of $\mathrm{Co}^{0} /\left(\mathrm{Co}^{2+}+\mathrm{Co}^{3+}\right)$ was also presented in Table 3. The highest $\mathrm{Co}^{\circ} /$ $\left(\mathrm{Co}^{2+}+\mathrm{Co}^{3+}\right)$ ratio was observed over Co/MesoZSM120 which showed higher reducibility and relative stability in FT synthesis. The wax deposition to catalyst deactivation in the mesoporous ZSM5 was also confirmed by XPS methods to quantify the amount of waxes or cokes on the surface of catalysts (Fig. 9). It can be noticed that the peak intensity of $\mathrm{C} 1 \mathrm{~s}$ increased with decreasing $\mathrm{Si} / \mathrm{Al}$ ratios, indicating the increased content of waxes or cokes on the catalyst surfaces. The lowest carbon content was showed over Co/Meso-ZSM120 catalyst. 

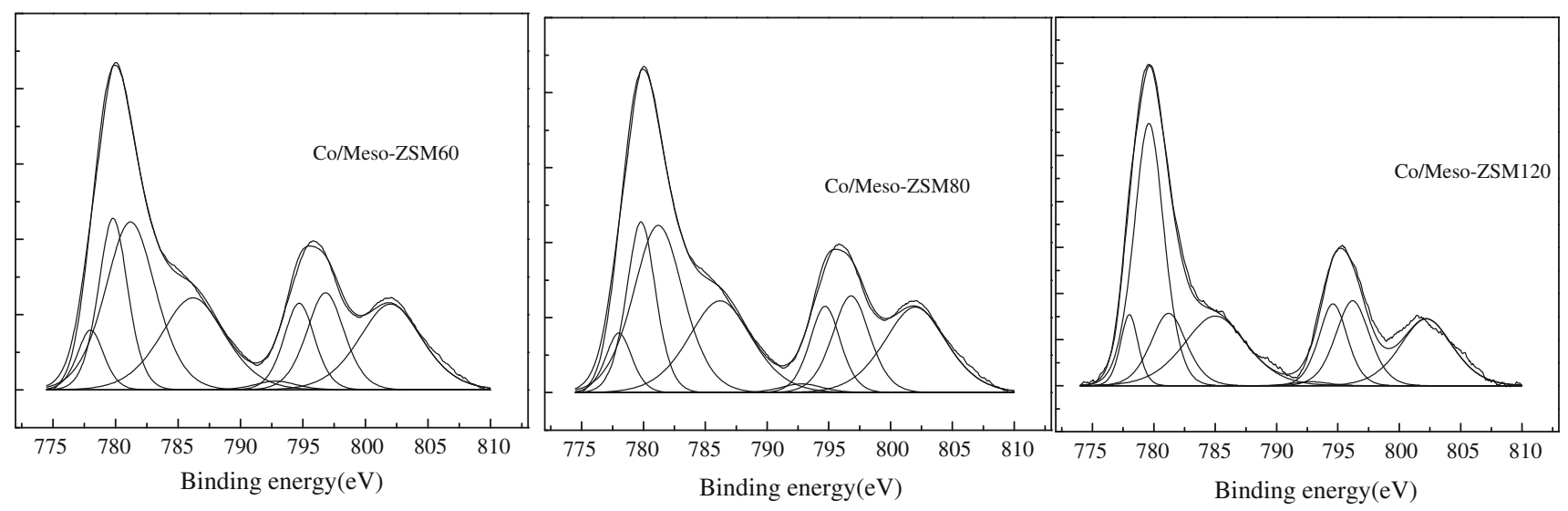

Fig. 8 XPS profiles of the used catalysts

Table 3 XPS results of cobalt catalysts

\begin{tabular}{|c|c|c|c|c|c|c|c|c|c|}
\hline \multirow[t]{2}{*}{ Sample } & \multicolumn{4}{|c|}{ Binding energy $^{\mathrm{a}} \mathrm{Co} 2_{\mathrm{p} 3 / 2}(\mathrm{eV})$} & \multicolumn{4}{|c|}{ Binding energy ${ }^{\mathrm{a}} \mathrm{Co} 2_{\mathrm{p} 1 / 2}(\mathrm{eV})$} & \multirow[t]{2}{*}{$\mathrm{Co}^{0} / \mathrm{Co}^{\mathrm{II}}+\mathrm{Co}^{\mathrm{III}}$} \\
\hline & $\mathrm{Co}^{0}$ & $\mathrm{Co}^{\mathrm{III}}$ & $\mathrm{Co}^{\mathrm{II}}$ & $\mathrm{Co}^{\mathrm{II}}$ satellite & $\mathrm{Co}^{0}$ & $\mathrm{Co}^{\mathrm{III}}$ & $\mathrm{Co}^{\mathrm{II}}$ & $\mathrm{Co}^{\mathrm{II}}$ satellite & \\
\hline $\begin{array}{l}\text { Co/Meso- } \\
\text { ZSM60 }\end{array}$ & $\begin{array}{l}778.06 \\
(407.6)\end{array}$ & $\begin{array}{l}779.53 \\
(891.7)\end{array}$ & $\begin{array}{l}781.32 \\
(1648.5)\end{array}$ & $\begin{array}{l}785.09 \\
(1131.4)\end{array}$ & $\begin{array}{l}792.8 \\
(101.5)\end{array}$ & $\begin{array}{l}794.77 \\
(742.3)\end{array}$ & $\begin{array}{l}796.46 \\
(915.1)\end{array}$ & $\begin{array}{l}802.64 \\
(1093.5)\end{array}$ & 0.082 \\
\hline $\begin{array}{l}\text { Co/Meso- } \\
\text { ZSM80 }\end{array}$ & $\begin{array}{l}778.06 \\
(164.7)\end{array}$ & $\begin{array}{l}779.63 \\
(580.5)\end{array}$ & $\begin{array}{l}781.20 \\
(327.4)\end{array}$ & $\begin{array}{l}785.09 \\
(403.8)\end{array}$ & $\begin{array}{l}782.8 \\
(35.936)\end{array}$ & $\begin{array}{l}794.67 \\
(279.3)\end{array}$ & $\begin{array}{l}796.24 \\
(232.6)\end{array}$ & $\begin{array}{l}802.23 \\
(303.1)\end{array}$ & 0.092 \\
\hline $\begin{array}{l}\text { Co/Meso- } \\
\text { ZSM120 }\end{array}$ & $\begin{array}{l}778.06 \\
(173.5)\end{array}$ & $\begin{array}{l}779.53 \\
(420.2)\end{array}$ & $\begin{array}{l}781.21 \\
(418.1)\end{array}$ & $\begin{array}{l}786.47 \\
(302.4)\end{array}$ & $\begin{array}{l}792.8 \\
(90.35)\end{array}$ & $\begin{array}{l}794.77 \\
(179.4)\end{array}$ & $\begin{array}{l}796.87 \\
(308.8)\end{array}$ & $\begin{array}{l}802.13 \\
(297.3)\end{array}$ & 0.137 \\
\hline
\end{tabular}

a The values in brackets denote the XPS peak area

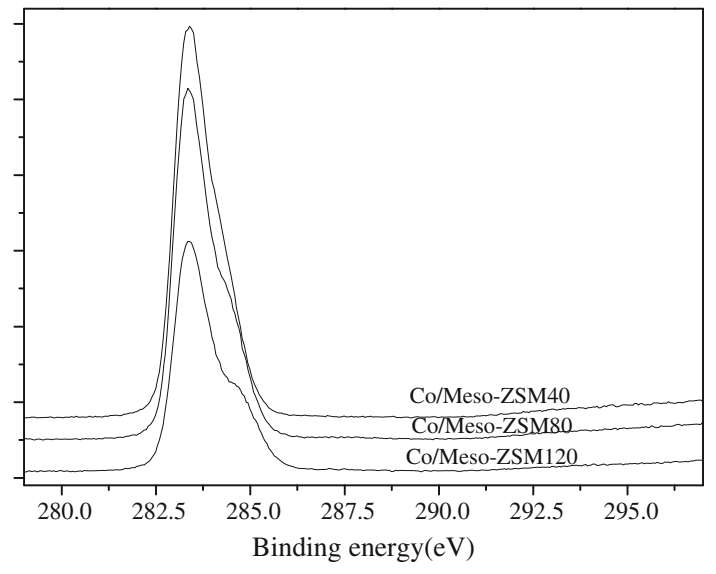

Fig. 9 XPS profiles of $\mathrm{C} 1$ s over the prepared catalysts

\section{Conclusion}

The effect of Si/Al ratios on hierarchal ZSM-5 for cobaltbased catalyst in FT reaction has been studied in this work. Co/Meso-ZSM60 catalyst showed higher selectivity to $\mathrm{C}_{5-18}$ hydrocarbons and higher olefin/paraffin ratio, which was attributed to smaller cobalt particles and larger number of weak acidic sites. For Co/Meso-ZSM120 catalyst, the reducibility of cobalt particles was higher and the concentration of weak acid sites was lower, consequently increasing $\mathrm{CO}$ conversion and $\mathrm{C}_{18}{ }^{+}$selectivity. The catalyst with perfect crystal structure of ZSM-5 favored products including water to accessibility and prevented cobalt particles from being oxidized compared to that of amorphous support, which was resulted in the lowest deactivation rate and the lowest carbon content on the surface.

Acknowledgments The work was supported by the National Natural Science Foundation of China (21106177, 21203232, 51204182), the Open funds of Key Laboratory of Biofuel (CASKLB201306) and The Basic Research Funds for Central University (2010QNA17), A Project Funded by the Priority Academic Program Development of Jiangsu Higher Education Institutions (PAPD).

\section{References}

1. W. Wang, Y. Chen, Appl. Catal. 77, 21-36 (1991)

2. E. Iglesia, S.L. Soled, R.A. Fiato, J. Catal. 137, 212-214 (1992)

3. E. Iglesia, Appl. Catal. A 161, 59-78 (1997)

4. G. Jacobs, T.K. Das, Y. Zhang, J. Li, G. Racoillet, B.H. Davis, Appl. Catal. A Gen. 233, 263-281 (2003) 
5. A.R. de la Osa, A. de Lucas, L. Sanchez-Silva, J. Diaz-Maroto, J.L. Valverde, P. Sanchez, Fuel 95, 587-598 (2012)

6. X. Li, K. Asami, M. Luo, K. Michiki, N. Tsubaki, K. Fujimoto, Catal. Today 84, 59-65 (2003)

7. A. Martınez, C. Lopez, Appl Catal A Gen 294, 251-259 (2005)

8. Y.W. Chen, H.T. Tang, J.G. Goodwin Jr, J. Catal. 83, 415-427 (1983)

9. H.H. Nijs, P.A. Jacobs, J. Catal. 66, 401-411 (1980)

10. P.A. Jacobs, in Catalysis by Zeolites, ed. by B. Imelik, C. Naccache, J.C. Vedrine (Elsevier, Amsterdam, 1980), pp. 293-297

11. G.H. Yang, J.J. He, Y. Yoneyama, Y.S. Tan, Y.Z. Han, N. Tsubaki, Appl. Catal. A Gen. 329, 99-105 (2007)

12. S. Kang, J. Ryu, J. Kim, I. Jang, A.R. Kim, G. Han, J. Bae, K. Ha, Energy Fuels 26, 6061-6069 (2012)

13. M. Hartmann, Angew. Chem. Int. Ed. 43, 5880-5882 (2014)

14. J. Perez-Ramırez, C.H. Christensen, K. Egeblad, C.H. Christensenand, J.C. Groen, Chem. Soc. Rev. 37, 2530-2542 (2008)

15. S.A. Lopez-Orozco, A. Inayat, A. Schwab, T. Selvam, W. Schwieger, Adv. Mater. 23, 2602-2615 (2011)

16. A.L.C. Pereira, J.M. González-Carballo, F.J. Pérez-Alonso, S. Rojas, J.L.G. Fierro, M.D.C Rangel, Top. Catal. 54, 179-189 (2011)

17. S. Sartipi, K. Parashar, M.J. Valero-Romero, V.P. Santos, B. Linden, M. Makkee, F. Kapteijn, J. Gascon, J. Catal. 305, 179-190 (2013)
18. J. Kang, K. Cheng, L. Zhang, Q. Zhang, J. Ding, W. Hua, Y. Lou, Q. Zhai, Y. Wang, Angew. Chem. 123, 5306-5309 (2011)

19. T. Witoon, M. Chareonpanich, J. Limtrakul, J. Sol-Gel. Sci. Technol. 51, 146-152 (2009)

20. Manoj Pudukudy, Zahira Yaakob, Superlattices Microstruct. 64, 15-26 (2013)

21. Masrinda Tasirin, Chem. Pap. 68, 1087-1096 (2014)

22. Manoj Pudukudy, Zahira Yaakob, Eng. J. 262, 1009-1021 (2015)

23. M. Pudukudy, Z. Yaakob, Z.S. Akmal, Appl. Surf. Sci. 330, 418-430 (2015)

24. J. Vernimmen, V. Meynen, S.J.F. Herregods, P. Cool, Eur. J. Inorg. Chem. 27, 4234-4240 (2011)

25. Agustın Martınez, Carlos Lopez, Appl. Catal. A Gen. 294, 251-259 (2005)

26. A. Tavasoli, R.M. Malek Abbaslou, A.K. Dalai, Appl. Catal. A 346, 58-64 (2008)

27. Y.J. Lee, J.Y. Park, K.W. Jun, J.W. Bae, Viswanadham N. Catal. Lett. 126, 149-154 (2008)

28. J.Y. Luo, M. Meng, X. Li, X.G. Li, Y.Q. Zha, T.D. Hu, Y.N. Xie, J. Zhang, J. Catal. 254, 310-324 (2008) 